\title{
Welding Simulation used in the Design of Metallic Armor Systems
}

\author{
Lee Fredette, PhD, $\mathrm{PE}{ }^{1 a^{*}}$, Elvin Beach, $\mathrm{PhD}^{2, \mathrm{~b}}$ \\ ${ }^{1}$ Battelle, 505 King Ave, Columbus, Ohio 43201, USA \\ ${ }^{2}$ Worthington Industries, Corporate Materials Laboratory, 905 Dearborn Drive, Columbus, Ohio \\ 43085, USA \\ âFredette@battelle.org, ${ }^{\mathrm{b}}$ Elvin.Beach@worthingtonindustries.com
}

\begin{abstract}
Keywords: Welding simulation, armor, metallography, finite element analysis, ballistic testing
\end{abstract}
\begin{abstract}
Welding steel armor reduces the armor material's protection capability. Several industrial and military welding standards exist for welding armor materials with the primary focus on joint strength rather than ballistic integrity.

The Heat Affected Zone (HAZ) created by the welding process introduces vulnerabilities in the protection system. The process and designs that we have demonstrated include mitigation features that eliminate the ballistic degradation and provide uniform protection across all armor materials.

In this study we used finite element simulation of the welding process to perform trade studies evaluating welded joint designs, and to show how the designs could be altered to both optimize armor performance and reduce welding heat input. Beneficial effects of reduced heat input, and the corresponding reduction in welding-induced residual stresses, created an overall reduction in distortion in the assembly and improvement of the armor performance.

The simulated welding process included the creation of the heat affected zone and the development of residual stresses in the structure. ABAQUS finite element software was used for the simulation with the aid of an extensive material property database created over the wide range of welding temperatures.

The finite element simulation predictions were validated and verified with excellent results by metallography and micro-hardness measurements. Live-fire ballistic tests were used as the final proof of measurable design improvements. Finite element welding simulation was shown to be an effective tool for improving upon standard welded armor designs, and above all in improving human safety.
\end{abstract}

\section{Introduction}

Military and peacekeeping forces need armor protection. Battelle has been working for many years to develop the lightest weight armor solutions available for many different vehicles. Standard practice in the industry is to follow the current military specification Ground Combat Vehicle Welding Code [1], which has been proven to degrade ballistic protection in welds used in the assembly of complex armor geometries.

Battelle has also worked with the US Nuclear Regulatory Commission research branch on a series of projects related to simulating welding-induced residual stresses in nuclear power plant primary cooling loop piping. The most recent project included an international round-robin study involving many organizations' participation in simulating and measuring the weld residual stresses developed in a series of mock-ups representing real nuclear piping components $[2,3,4,5]$. The welding simulation results from the round-robin participants correlated well with each other, and with detailed measurements using various techniques. The promising results of this study encouraged us to apply the welding simulation methods used in these mock-up programs to other projects. The welding related issues found in the armored vehicle designs were an ideal match for this type of simulation. 
Ballistic armor strength can be defined by its resistance to penetration by a specific armament threat fired at a specific distance. A military standard (MIL-STD-662F) [6] gives guidelines for determining the ballistic resistance of armor against small arms fire. This specification defines the ballistic limit $\left(\mathrm{V}_{50}\right)$ as the velocity at which a particular projectile would completely penetrate a specific armor or partially penetrate the armor with equal likelihood. The $\mathrm{V}_{50}$ value is an average calculated using measured impact speed data. An equal number of the highest speed impacts causing partial penetration and the slowest speed impacts causing full penetration are averaged. As an example, the specification lists a range of impact speeds at a distance 100 meters in the range of $1,950 \mathrm{fps}(594 \mathrm{~m} / \mathrm{s})$ to $3,400 \mathrm{fps}(1,036 \mathrm{~m} / \mathrm{s})$ depending on the projectile used in the test.

Welding reduces an armor assembly's $\mathrm{V}_{50}$ number, meaning that it reduces the range at which the armor is effective. The armor tested in this study shows a reduction in $V_{50}$ performance of 200 fps $(61 \mathrm{~m} / \mathrm{s})$ using the industry standard armor welding procedure. This reduced performance means that to provide safe coverage the armor must remain 100 to 200 meters further from the threat than non-welded armor.

We used finite element welding simulations to create welded joint designs that eliminate this vulnerability, and also improved the protection level over a plate of steel armor containing no welds.

\section{Geometry}

The T-Joint geometry is often encountered in welded armor systems. It is typically assembled with fillet welds on both sides of the joint between the two perpendicular plates of steel. Figure 1 shows the geometry of one of the test panels used in this project. The steel plates are $0.312 \mathrm{in}(7.9 \mathrm{~mm})$ thick. The base plate is $6 \mathrm{in}$ by 20 in $(152.4 \mathrm{~mm} \times 508 \mathrm{~mm})$ and the perpendicular plate, called a return, is 2 in $(50.8 \mathrm{~mm})$ high and runs the length of the base plate.

While several geometries were studied, the focus of this paper will be on two of the successful T-Joint designs. We will discuss the differences in the ballistic performance between a single un-welded base plate, the traditional industry standard fillet welded TJoint, and two new concepts developed using welding simulation studies.

An initial study was performed on the traditional geometry, which would use full

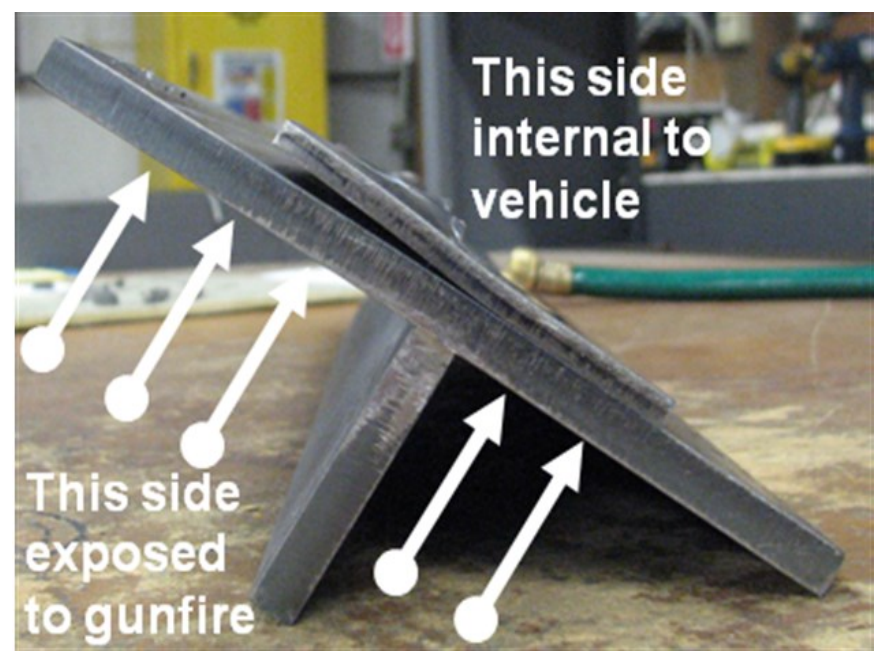

Figure 1 Armor Test Panel with T-Joint fillet welds on both sides of the T-Joint to join the panels. This study was undertaken as a proof of concept effort to show that welding simulation could be used to evaluate the welded armor design. Two somewhat obvious observations were made from the results of these welding simulations. Welding residual stress degrades ballistic performance when it puts the struck surface in tension, reducing the additional stress that the assembly can withstand before failure occurs. And secondly, that welding induced temperatures change the heat treatment of the armor material and reduce its protection capability to the range of standard structural steels when heated above $1,000^{\circ} \mathrm{F}\left(538^{\circ} \mathrm{C}\right)$. This simulation provided quantitative values to support these observations throughout the geometry and allowed for simple sensitivity studies to be performed. Several geometries that mitigate these performance reducing characteristics were developed.

The traditional, industry standard design using fillet welds results in high residual tensile stress on the struck side of the armor panel indicating that welding should be carried out on the opposite side of the armor panel. The standard fillet weld design also creates a heat affected zone (HAZ) that 
leaves material with degraded armor protection through the thickness of the assembly. Reducing heat input would reduce the size of the HAZ and therefore improve the design as well.

Figure 2 shows one of the new concept test panels that includes features addressing the need to reduce tensile residual stresses on the struck side of the armor while reducing heat input and moving most of the joining welds to the back side of the armor plates. Instead of full fillet welds which run the length of the panel joining the return to the base, this panel has fillet stitch welds on one side of the return which skip areas to reduce heat input. The fillet stitch welds are 1 in $(25.4 \mathrm{~mm})$ long, and separated by 2in $(50.8 \mathrm{~mm})$ with this pattern repeated for the length of the panel. There are rectangular holes in the base plate which are filled with plug welds to join the

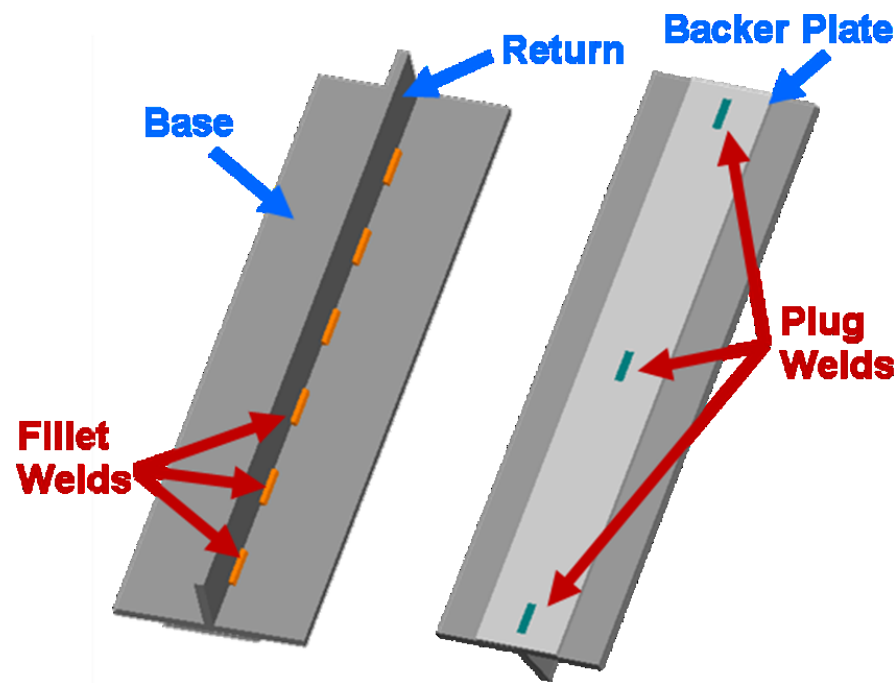

Figure 2. Test Panel with 3 Plug Welds and Fillet Stitch Welds return to the base. This feature also reduces the total heat input to the assembly and moves the welding to the back of the armor panel. A backer plate 0.19 in thick $(4.8 \mathrm{~mm})$ of standard non-armor structural steel (ASTM A36) is used to facilitate the plug weld operation. The skipped areas in the fillet welds correspond with the plug welds on the back side, so that no area of the armor panel assembly is welded on both the front and back side in the same area. The test panel shown will be referred to as the 3-plug configuration. The second concept contains seven plug welds in the entire span and no fillet welds. This will be referred to as the 7-plug configuration.

\section{Material Properties}

Two sets of material properties were used in the thermal and structural analyses of the welded assemblies. The backer plate and weld material was simulated using properties of annealed standard structural steel corresponding to ASTM A36. The armor plates were modeled using material properties of MIL-DTL-46100, Class I high hard steel [7], and AISI 8630 triple alloy steel which has a similar chemistry and for which strength vs. temperature data is readily available, (DIN 1.6545).

Figure 3 illustrates the temperature dependent elastic plastic properties for the armor material based on scaling available curves for AISI 8630 behavior vs. temperature to the higher strength properties of the MIL-DTL-46100 steel. The armor material specification requires a Brinell hardness range of HBW 477 -534 (49.5-53.5 Rockwell C), a minimum room temperature yield strength of $190 \mathrm{ksi}(1,310 \mathrm{Mpa})$, and an ultimate strength of $240 \mathrm{ksi}(1,655 \mathrm{Mpa})$ with a $\geq 10 \%$ strain to 
failure. The ABAQUS [8] isotropic material hardening laws were followed using the material true stress-strain data presented here. Stress relieved and annealed material must be used for the elasticplastic tensile properties of the weld material. The welding simulation process subsequently creates work hardening of the material. Finally, a set of additional material properties that vary with temperature were used including the following: elastic modulus, thermal conductivity, specific heat, coefficient of thermal expansion, and simulated zeroing of stresses and strains at $2,500^{\circ} \mathrm{F}\left(1,371^{\circ} \mathrm{C}\right)$. Modeling phase transformation effects were beyond the scope of this project and were ignored. They have been successfully modeled with user created ABAQUS material property subroutines and used in previous projects. Our experience suggests that, for very large distortion control welding analyses, the effect of phase changes on the final distortions are often not important, even for high carbon steels.

\section{Analysis}

The simulated welding produced residual stresses were calculated using a three dimensional model. The finite element model was subjected to a thermal analysis, which simulated the weld process functions of laying down the molten beads of weld filler metal, introducing heat energy into the weld bead and cooling the weld to an appropriate interpass temperature $\left(\leq 350^{\circ} \mathrm{F}\right.$, or

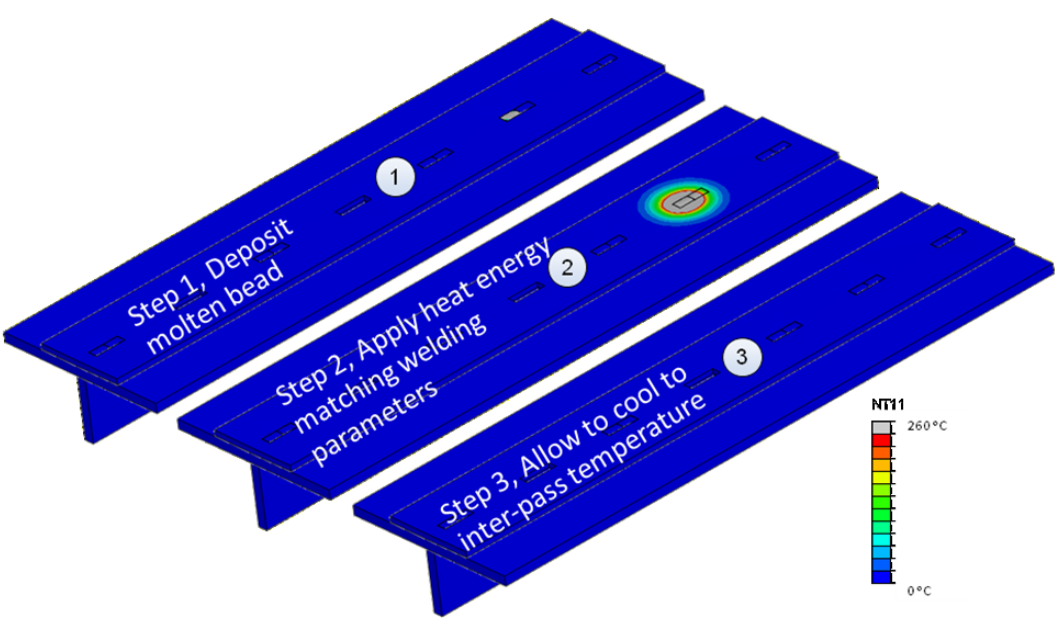

Figure 4. Weld Simulation Sequence $\left(0-260^{\circ} \mathrm{C}\right.$ scale $)$

$177^{\circ} \mathrm{C}$ ) as specified on the assembly drawing. The thermal analysis calculated the temperatures throughout the finite element model during the welding process. A subsequent stress analysis was performed, which used the previously defined temperatures to calculate the elastic-plastic residual stresses and strains in the welded geometry due to the thermal effects of welding. ABAQUS finite element software was used throughout the study. Material properties used in the analyses varied with temperature and made use of the annealing simulation capabilities of the ABAQUS software to model weld bead melting.

Figure 4 shows the welding simulation sequence in a three step process for the transient thermal analysis and a corresponding three step process for the subsequent stress analysis drawing temperatures from the previous step. A molten bead was deposited. Heat was applied based on the welding parameters and the speed of travel used in

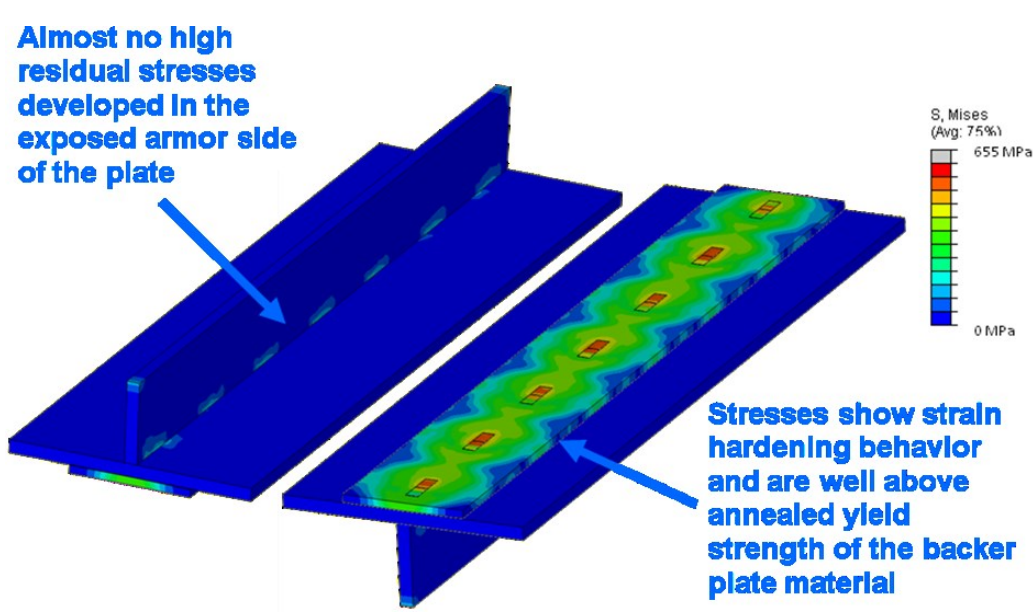

Figure 5. Von Mises Stress plot of 7-Plug Weld Panel, 0 - 95ksi range $(0-655 \mathrm{MPa})$ depositing the weld, and finally the weld was allowed to cool to the interpass temperature before the process is repeated until all of the welding passes were complete. The plug welds were preformed in two lumped passes, and the fillet stitch welds were each done in a single lumped pass. Heat input 
values of 26 Volts and 260 Amps were measured during the welding process. A welding efficiency of $75 \%$ was assumed. The amount of energy delivered in each lumped pass was calculated based on the welding wire cross sectional, feed rate, and power input to the welding process. The timing of the steps was made to match realistic values found in the actual process. The weld sequence matched the actual weld procedure. A realistic convection coefficient was assined to the structure's surfaces to draw heat away from the welds.

Stress, temperatures and deflections were evaluated for each of the two concept designs using the finite element models. Figure 5 shows the Von Mises stress plot for the T-Joint panel with seven plug welds and no fillet welds. The plot shows that almost no high residual stresses are present in the struck side of the panel, and that stresses in the $90 \mathrm{ksi}(620 \mathrm{MPa})$ range are present in the plug welds on the opposite side from the threat. Stresses are above the annealed yield strength in the ASTM A36 backing plate, but this is of no concequence in terms of the armor performance. The residual stress plot for the concept with three plug welds and the additional fillet stitch welds looks similar except that it has residual tension stresses of $140 \mathrm{ksi}$ (995Mpa) in the areas around the fillet welds, causing concern for degraded ballistic performance caused by these features.

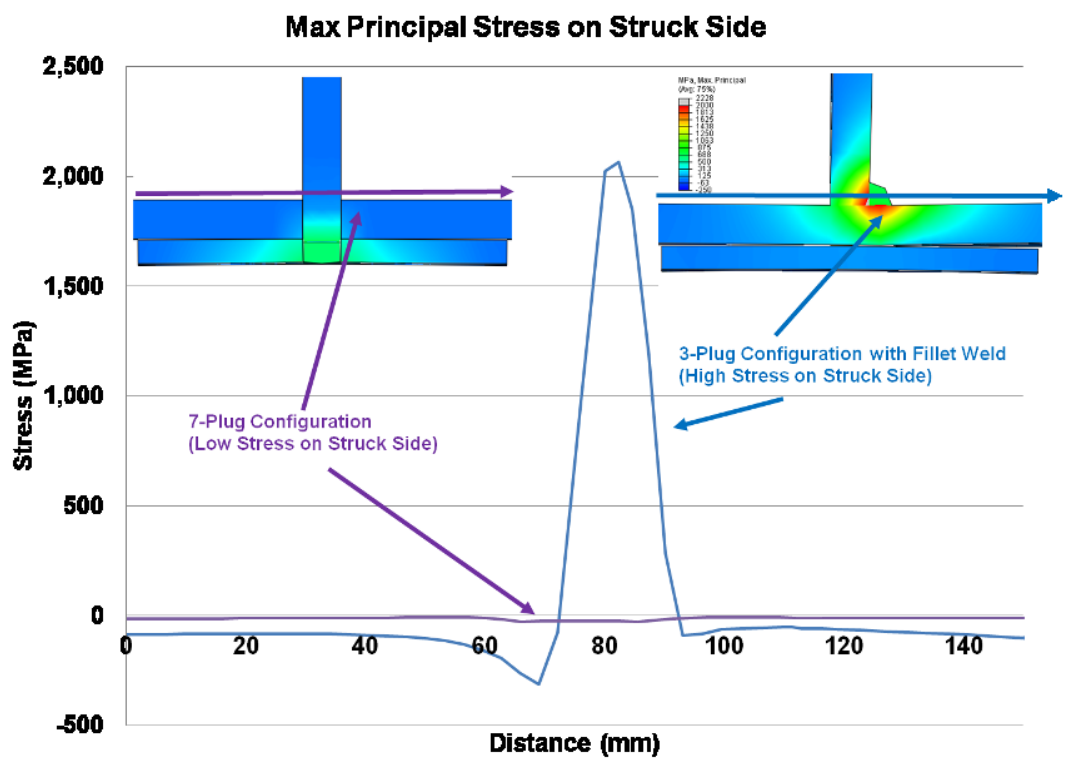

Figure 6. Max Principal Stress Comparison on Struck Surface

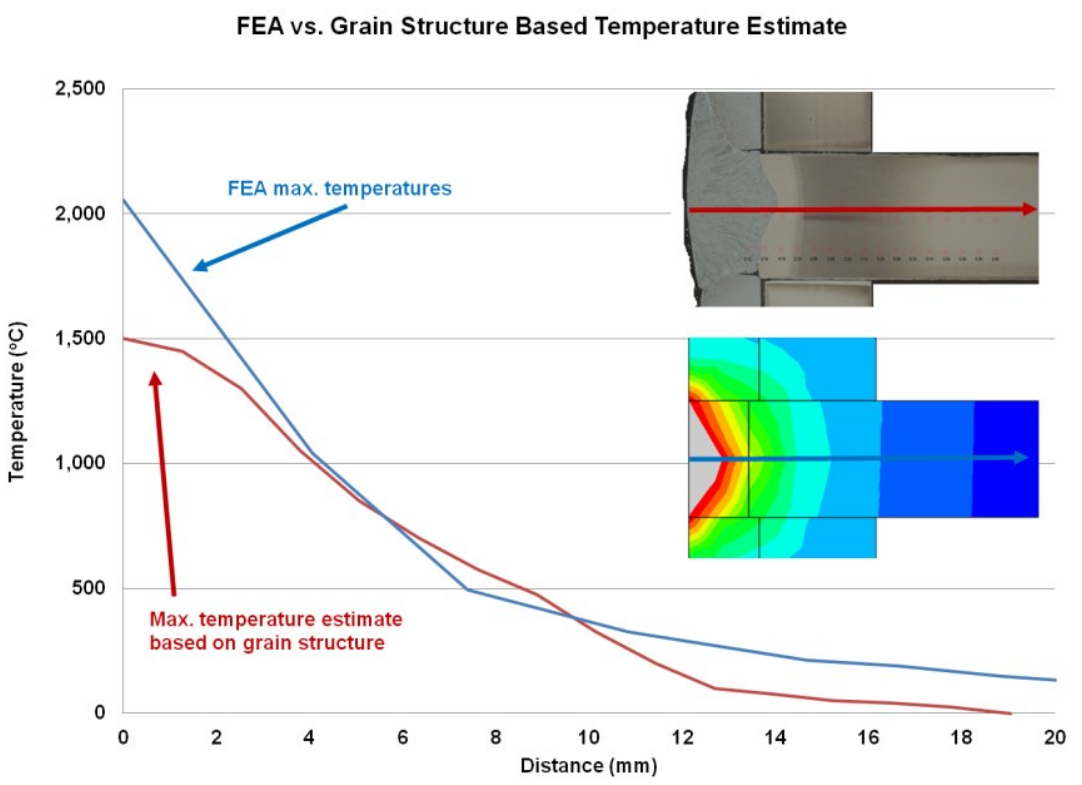

Figure 7. Max. Temperature Estimates in the 7-Plug Weld

Figure shows a plot of the maximum principal stress along the indicated path wich traverses the struck side of the sample armored plates. The graph and stress plots compare the resulting residual stress in the two designs under consideration. The 7-plug weld design, shown on the left, is effective in reducing the residual stress found on the struck side of the panel to nearly zero. The 3plug weld design with additional fillet stitch welds on the struck side shows high residual stresses, beyond the range of the room temperature yield strength of the armored material, in the area of the filet weld. The 7-plug weld design would be expected to perform better than the 3-plug design due to the lower residual stress on the struck side.

Metallographic samples were made from the two design concepts. A wire EDM machine was used to cut slices through the welded areas. These samples were subsequently polished and etched for microstructure examination. Microhardness measurements were made through the weld areas 
and into the parent metal until the hardness reached the acceptable limits per MIL-DTL-46100. The microhardness measurements showed degraded hardness below the acceptable limits in the areas roughly equivalent to the visible heat affected zone in the etched samples. The parent material retains its hardness on the struck side of the T-Joints at all locations in the 7-plug weld configuration, and in all areas except in the fillet weld areas of the 3-plug weld configuration.

Though microhardness measurements showed degraded properties in the heat affected zones, the range of hardness variation was small. However, there was a more dramatic finding related to the temperature estimates found in the metallographic study and the simulations. Figure and Figure show estimates of the maximum temperature experienced by the assemblies through the welding process. One estimate was based on examining the microhardness data, the microstructure and the phases observed in the etched cross sections, and the other was based on the maximum temperature found in the finite element models. These estimates were done independantly, and then compared.

The first graph shows the results for the 7-plug design with the path indicated on the photos. The microstructure-based maximum temperature estimate closely matches the FEA model. The graph shows that the location that experienced $1,000^{\circ} \mathrm{F}\left(538^{\circ} \mathrm{C}\right)$ or higher is limited to the side of the $\mathrm{T}$ Joint opposite the struck side, and only penetrates the assembly a total of $0.325 \mathrm{in}$ including the backer plate. Therefore, less than half the thickness of the armor plate is penetrated by the heat affected zone. This means that the area of degraded armor in this case is almost completely contained behind the protective outer surface and the return component.

The second graph shows a similar estimate along a different path in the 3-plug weld configuration with the fillet welds. The path traverses the armor plate under the fillet

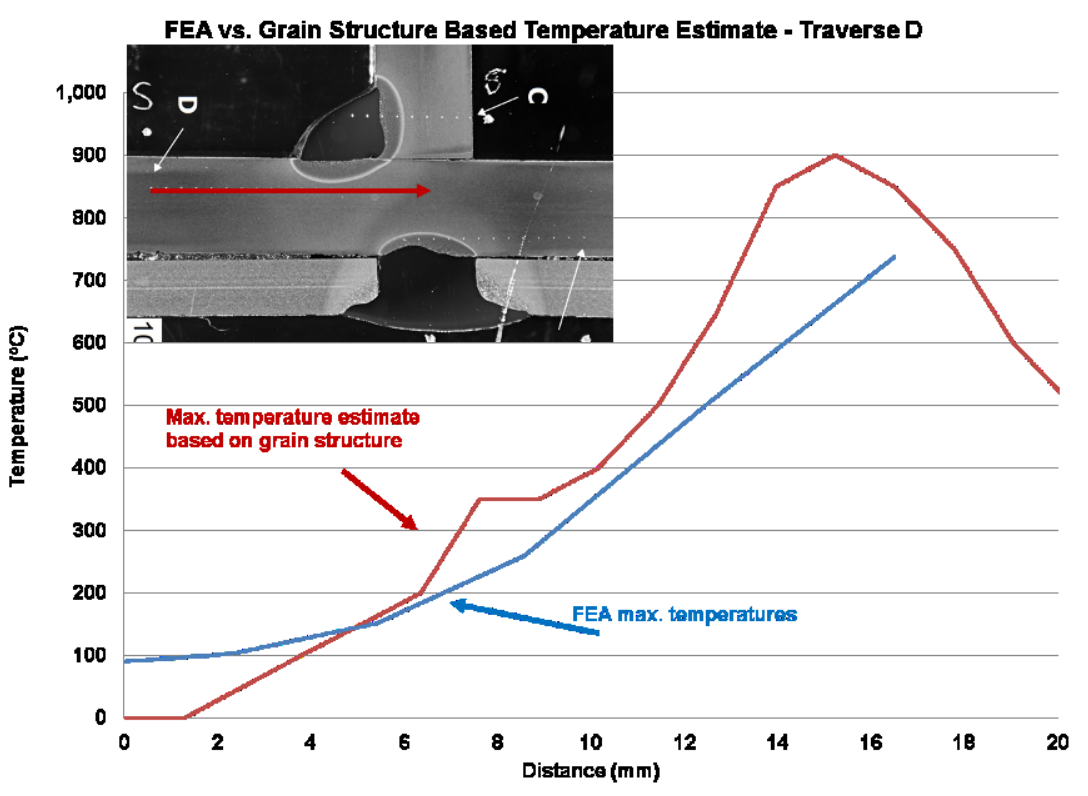

Figure 8. Max Temperature Estimates in the 3-Plug Weld weld as indicated in the photo accompanying the graph. Again, the match between the finite element simulation estimate and the metallographic estimate is very good. There is an area indicated that shows degraded armor material properties under the fillet weld. The fillet welds were not supposed to align with the plug welds for this design, but in this cross section they obviously have. This could lead to a degraded armor path through the entire panel at this location.

Figure shows the test results that are the final measure of the armor design's quality. The graph shows the ballistic limit speeds as calculated by the method described in MIL-STD-662F [6] from live-fire tests. All shots used in the ballistic testing struck the welded portion of the panels. The base armor plate alone, with no welding, had a ballistic limit of 3,032 fps $(924 \mathrm{~m} / \mathrm{s})$, while the traditional fillet weld T-Joint design had degraded performance of $2,825 \mathrm{fps}(861 \mathrm{~m} / \mathrm{s})$. This can mean that as much as $100-200$ meters of additional stand-off distance would be required depending on the small arms fire threat. Both concept designs outperformed the unwelded base plate with the 7-Plug configuration achieving a ballistic limit of 3,168 fps $(966 \mathrm{~m} / \mathrm{s})$ and the 3-plug concept achieving a slightly lower 3,100 fps $(945 \mathrm{~m} / \mathrm{s})$ value. The ballistic limit for the 3-plug configuration was expected to be lower than that of the 7-plug configuration due to the added heat input created by the fillet stitch weld based on the simulation results, but both concepts outperformed the traditional welding procedure. 


\section{Conclusion}

Finite element simulation was successfully used to perform sensitivity studies on three welded $\mathrm{T}$ Joint armor panels. These designs are currently being used on two armored vehicles in production. Parameters of weld residual stress, and welding induced temperatures were used as measures of design quality. We created new concepts that both decreased tension residual stresses on the struck side of the armor, and decreased the total volume of damaged armor by reducing and localizing the areas of high temperature produced in the welding procedure. These results

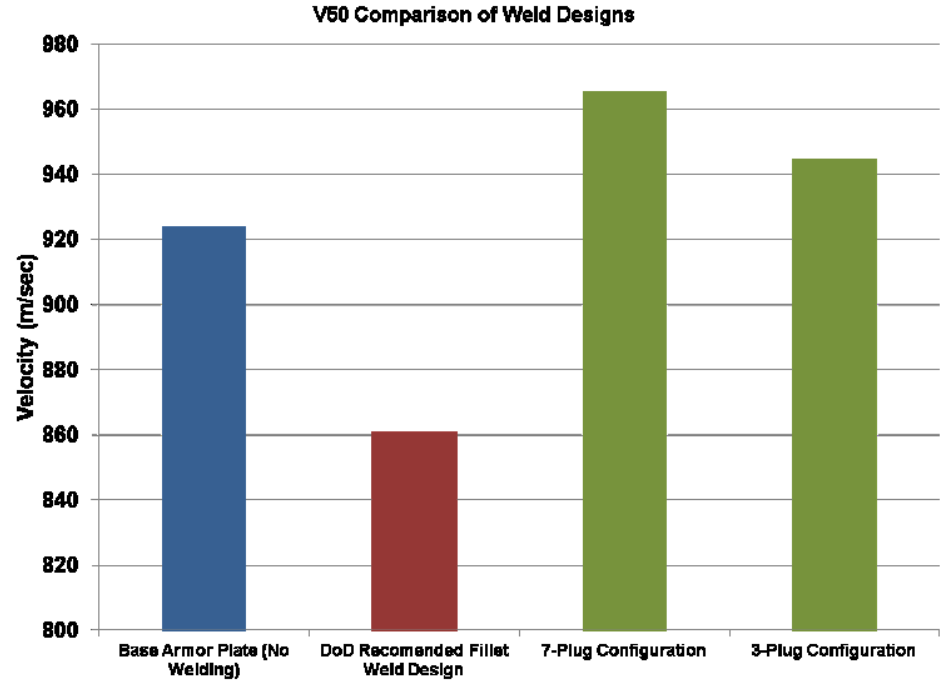

Figure 9. Live-Fire Ballistic Testing Comparison can be used as general guidelines for armor weld designs or as a starting point for good analytical weld design optimization. Good correlation between estimates made with metallographic samples, and the finite element simulations was found in the total extent of the heat affected zones.

Welding simulation can be effectively used to perform sensitivity studies to assess the effect of change in weld sequence and assembly constraints to reduce distortion, and the change of weld bead number and configuration to reduce the heat input. All of these factors can be used to improve welded designs.

With further refinement of the material definitions, this process could be expanded to include a dynamic impact simulation to actually model the ballistic impact to supplement costly live-fire testing when performing sensitivity studies on a new design.

\section{References}

[1] Ground Combat Vehicle Welding Code - Steel- 1249550, US Army Tank-Automotive and Armaments Command, (2006)

[2] L. Fredette, M. Kerr, H. Rathbun, J. Broussard, NRC/EPRI Welding Residual Stress Validation Program - Phase III Details and Findings, PVP2011-57645, ASME PVP Proceedings, (2011) [3] H. Rathbun, L. Fredette, D. Rudland, NRC Welding Residual Stress Validation Program International Round Robin Program and Findings, PVP2011-57642, ASME PVP Proceedings, (2011)

[4] M. Kerr, H. Rathbun, Summary of Finite Element (FE) Sensitivity Studies Conducted in Support of the NRC/EPRI Welding Residual Stress (WRS) Program, PVP2012-78883, ASME PVP Proceedings, (2012)

[5] Weld Residual Stress Finite Element Analysis Validation: Part 1 - Data Development Effort, U.S. Nuclear Regulatory Commission Office of Nuclear Regulatory Research, NUREG-2162, NRC ADAMS Accession Number ML14087A118, (2014)

[6] MIL-STD-662F, Department of Defense Test Method Standard, V50 Ballistic Test for Armor, (1997)

[7] MIL-DTL-46100E, Detail Specification, Armor Plate, Steel, Wrought, High Hardness, (2008)

[8] ABAQUS, V6.12-3, Dassault Systèmes, Providence, RI, (2012) 